\title{
EU Economic Fluctuation Synchronization: Evidence from Five Sample EU Economies
}

\author{
Guangxu Li, Junrong Liu* \\ Trans-Himalaya Studies Center, Leshan Normal University, Leshan, China \\ Email: *Liujr@lsnu.edu.cn
}

How to cite this paper: $\mathrm{Li}, \mathrm{G} . \mathrm{X}$. and $\mathrm{Liu}$, J.R. (2018) EU Economic Fluctuation Synchronization: Evidence from Five Sample EU Economies. Modern Economy, 9, 699-710. https://doi.org/10.4236/me.2018.94045

Received: March 18, 2018

Accepted: April 21, 2018

Published: April 24, 2018

Copyright $\odot 2018$ by authors and Scientific Research Publishing Inc. This work is licensed under the Creative Commons Attribution International License (CC BY 4.0).

http://creativecommons.org/licenses/by/4.0/

\section{cc) (i) Open Access}

\begin{abstract}
This paper, which is based on the five major economies of European Union, France, Germany, Holland, Luxembourg, Sweden and United Kingdom, is dedicated to the empirical analysis on synchronization of economic fluctuation in the European Union (EU). The research conclusions show that during the period spanning from 1971-2016, the synchronization of EU economic fluctuations is significant, while the deepening of regional integration witnesses the gradual enhancement of the synchronization in the EU. Meanwhile, the research also shows that some dis-synchronization has been existing within EU, which indicates the presence of the discordance in EU economic policies and regional cooperative mechanism.
\end{abstract}

\section{Keywords}

EU, Economic Fluctuation, Synchronization

\section{Introduction}

With the globalization deepening, regional and international economic fluctuation synchronization has been shed light on for current years. Researches on economic fluctuation synchronization have their great economic and managerial implications for both international, national and entrepreneurial management and risk control. In international regime, economic fluctuation synchronization at least manifests the trend of economic integration of economies with economic or politic coalition and hence leads to international policy compromising and temporization or further integration. In national regime, with awareness of economic fluctuation synchronization with other economies, the country will work on the international cooperation and risk-control conducted through the international synchronization. In corporate level, economic fluctuation synchroniza- 
tion brings firms (particularly transnational corporations) the enlarged and promising profitable market in booming season while makes entrepreneurs suffer the cramped elbow-room in recession time, and the cooperations will act accordingly to the situation exerted by economic fluctuation synchronization.

With the previous statement presenting the importance of the study over economic fluctuation synchronization, the article is devoted to exploring the economic fluctuation synchronization in European Union (EU) based on such five major economies as France, Holland, Luxembourg, Sweden and the UK, which are a very representative mix of EU economies. The article estimates the annual economic synchronization index (1990-2016) of EU sample economies, which clearly characterize the EU economic fluctuation synchronization. However, the small sample capacity even with the most typicality still proves to be insufficient in stringency.

The article organization goes as follows, the literature to argue economic fluctuation synchronization will be recalled in the next section, and we present our empirical methodology employed in Section 3 and the analysis based on trend comparison and correlation in Section 4. And the analysis based on C-M synchronization index method (Cerqueira and Martins' method) is to be engaged in Section 5, while Section 6 concludes.

\section{Literature Review}

Economic fluctuation synchronization is a comprehensive expression about economic synchronization and interaction existing among different economies. Scholars [1] [2] [3] [4] [5] have already made a large number of theoretical and empirical researches about economic fluctuation synchronization. On the EU economic synchronization study, scholars mainly focus on analyzing economic synchronization analysis between China and the EU, but the studies on the economic fluctuation synchronization among the EU members are relatively small. $\mathrm{EU}$ is a long-standing entity, with a history of eighty years since the beginning of coal and steel alliance in 1940s; it has developed into the highest form of regional economic integration, among humans. There are two key points in the latest 30 years of evolution: first, in December 1991, the European summit approved the "Treaty of European Union", which officially entered into force in November 1993, it marked the official birth of the EU; second, in 1999, the Euro operated, and in January 2001, coins and paper notes were issued. The results of these major events were surely reflected in the synchronization level of economic fluctuations among the EU member countries. In view of this, this paper mainly analyzes economic fluctuation synchronization level among EU economies in 1990-2014 and explores the changing tendency of this level.

At present, there are many differences about the definition of synchronization among academic circles, so a consensus has not been reached yet. Zhou Yangmin [6] translates it into Synchronization or Co-movement. Liu Chongyi [7] holds that the essence of economic fluctuation synchronization is equal to the 
consistency of economic fluctuation (including synchronization). Zhang Bing [8] suggests that economic fluctuation synchronization means fluctuations taking place at the same period, which implies that the fluctuation time; the amplitude and the length of different economies are on the same level. Ren Zhixiang [9] believes that the focus of synchronization lies in interaction, such kind of interaction and synchronization form the two aspects of the economic cycle. Wang Yue (2007) is more inclined to think that economic cycle synergy is synchronization or relevance. But some foreign scholars (Stock and Watson Backus, Kehoe and, 2005; Kydland, 1992) regard economic fluctuation synchronization as correlation, and use relevant coefficient to measure synchronization level. They suggest that economic fluctuation synchronization refers to those economies which have appeared nearly simultaneously.

Many scholars [10] [11] are engaged in the study of EU economic synchronization. Qin Aihua [10] studies the economic cycle convergence of EU members; the research indicates that European economic integration level is positively related with economic cycle convergence within EU members. Sun Jin and Cai Tongjuan [11] hold that since 2007, EU economic synchronization is remarkable, but there exist differences in synchronization between different countries. Jason Jones and Nora Collins [12], Weyerstrass, K., van Aarle, B. and Kappler, M. [13] make use of empirical data to certify the economic cycle correlation or synchronization between EU members from different angles.

Based on the topic of this paper, the authors accept that the definition of synergy is Synchronization, and choose some typical EU economies such as France, Holland, Luxembourg, Sweden and UK as samples to study internal economic fluctuations among EU member nations. We have chosen to study and conduct detailed analysis on these five economies within EU, because, in our opinion, they have the most versatile and robust economies within European Union.

\section{Research Data and Methods}

The data which this paper uses, is the economic growth rate of sample countries from 1971-2016. Economic growth rate is the core index which measures economic fluctuation. Many scholars [8] [11] [14] [15] use this index to study international and regional economic synchronization. The GDP growth rate data of countries all comes from the International Monetary Fund online database.

The main methods of the paper are correlation analysis and C-M synchronization index method. Correlation analysis is a very simple method; this method can show the economic fluctuations situation between EU sample countries. C-M synchronization index calculation method is more complicated but can show economic fluctuations synchronization of sample countries more scientifically and objectively.

C-M synchronization index method is used by Cerqueira and Martins [14] for the first time, and the specific calculation formula of synchronization index is as follows: 


$$
\rho_{i j, t}=\left(1-\frac{1}{2}\left(\frac{d_{j, t}-\bar{d}_{j}}{\sqrt{\frac{1}{T} \cdot \sum_{t=1}^{T}\left(d_{j, t}-\bar{d}_{j}\right)^{2}}}-\frac{d_{i, t}-\bar{d}_{i}}{\sqrt{\frac{1}{T} \cdot \sum_{t=1}^{T}\left(d_{i, t}-\bar{d}_{i}\right)^{2}}}\right)^{2}\right)
$$

Herein, the related indexes are defined as follows:

$\rho_{i j, t}(-\infty, 1]$ is synchronization index, the level of economic fluctuation synchronization of country $i$ and country $j$ in the period of $t$. The greater value is, the more obvious economic fluctuation synchronization among countries is.

$d_{i, t}, d_{j, t}$ respectively signify the growth rates of GDP of country $i$ and country $j$ in the period of $t$.

$\bar{d}_{j}, \bar{d}_{i}$ respectively signify the average growth rates of GDP of country $i$ and country $j$ in the period of $t$.

$T$ is period number in the inspection period (annual number).

The formula is modified by Michael Artis and Toshihiro Okubo (2011), and then the calculation method of extended C-M synchronization index is obtained:

$$
r_{i j, t}=\frac{1}{2} \log \left(\frac{1}{1-\rho_{i j, t}}\right)
$$

The value range of revised synchronization index $r_{i j, t}$ is $(-\infty,+\infty]$, then overcoming the problem of asymmetric synchronization index value calculated by the original formula. When $r_{i j, t}$ is positive, it indicates that co-positive correlation, otherwise is co-negative correlation. The greater the value of $r_{i j, t}$ is, the stronger is the economic fluctuation synchronizations of the two countries under consideration. Vice versa, the weaker the synchronizations the lesser is the value of $r_{i j, t}$.

\section{Analysis Based on Trend Comparison and Correlation}

The economic growth data of France, Holland, Luxembourg, Sweden and the UK is shown in Figure 1. The economic growth trend shows that, in 1971-2016, the five countries were on the cooperative fluctuations trend overall. A visual observation of Figure 1 finds that, the fluctuation differences of the economic growth of all countries in 1971-1992 (time difference and amplitude difference) are higher than those of 1993-2001, while in 2002-2016, the time synchronization of economic growth fluctuation is in high level, average amplitude differences drop down. This indicates that with the gradual sublimation of European economic integration, the synchronizations between economies, improve significantly.

To further intuitively display the economic fluctuation synchronizations in France, Holland, Luxembourg, Sweden and the United Kingdom, the authors conduct a five-moving average processing of the original data. Figure 2 shows 


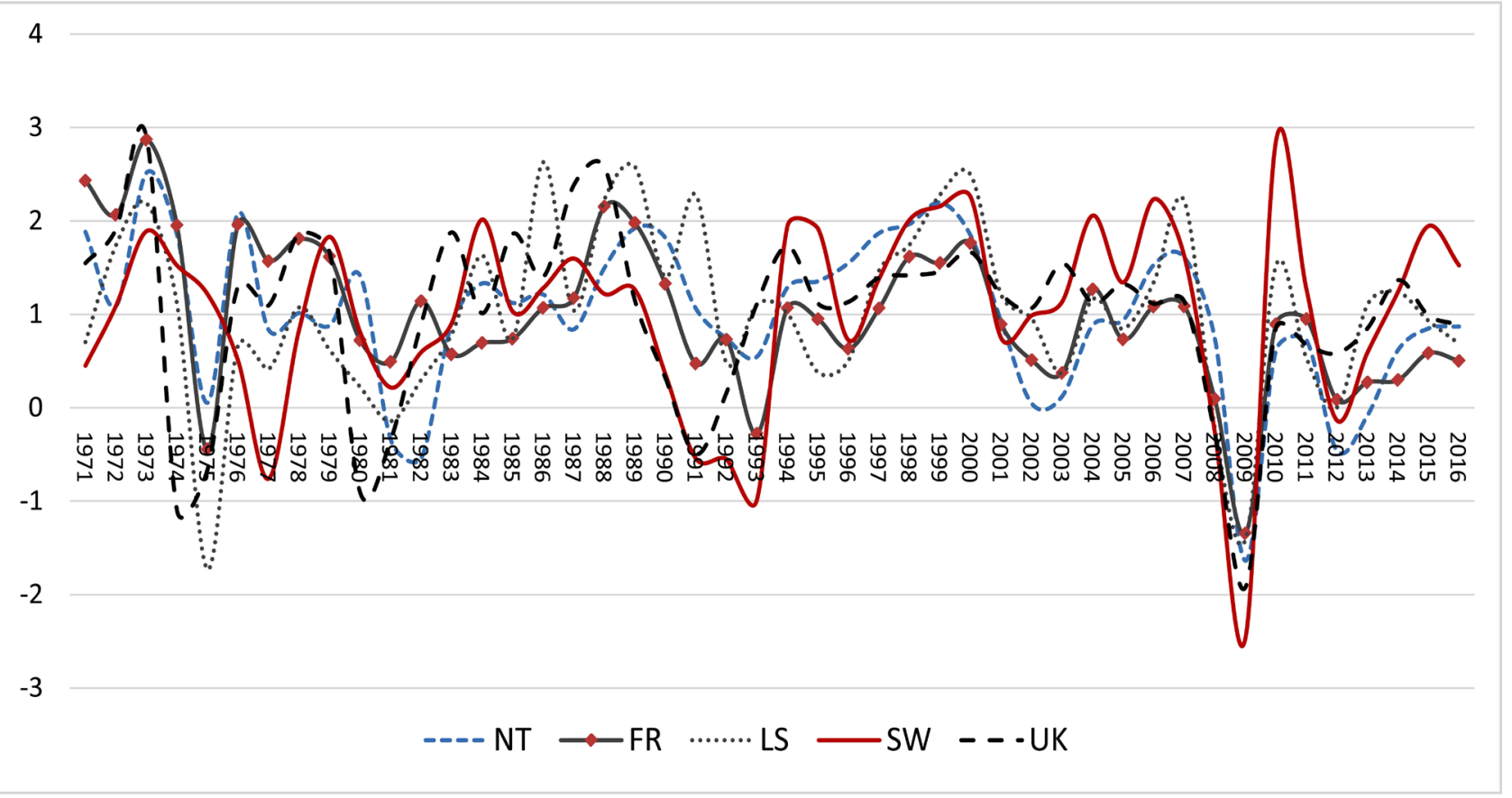

Data source: the original data is from the online database of UNCTAD.

Figure 1. The fluctuation trends comparison of economic growth in some EU countries.

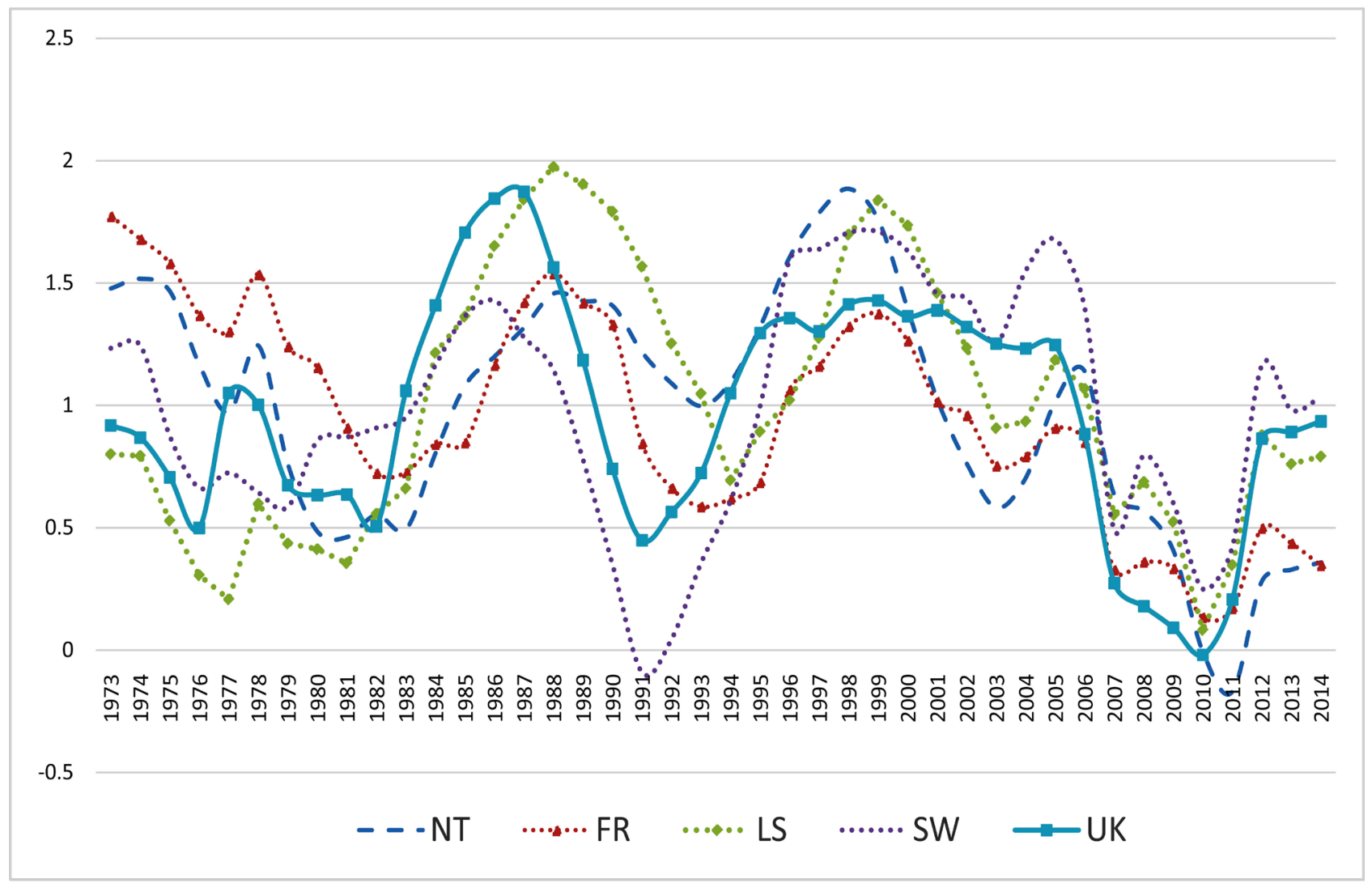

Data source: the original data is from the online database of UNCTAD.

Figure 2. The 5 moving average trend comparison of economic growth of $5 \mathrm{EU}$ countries. 
the trend comparison of the economic growth rate of five countries after processed by five moving average. The comparison results show that the economic growths of France, Holland, Luxembourg, Sweden and the UK experience are generally similar to three economic cycles, occurring in 1973-1987, 1988-1997, and 1998-2013. According to the normal economic development trends, in 1998-2008, a complete economic cycle will form. But during 2007-2008, there was the global financial crises which originated from US sub-prime mortgage crisis. This 2007-2008 crisis perturbed global economic growth. European countries also suffered from attack: in 2015 the economic growths of these countries have not recovered to the level of 2005. In fact, based on the observation of the economic growth trend in France, Holland, Luxembourg, Sweden and the United Kingdom in 1998-2015, we find that the five countries have experienced two common economic cycles of 1998-2005 and 2006-2015.

The author conducts a Pearson correlation test of the economic growth data after a five-point-moving average. The correlation test results of economic growth rate in 1973-2015 are shown in (Table 1), the economic growth correlation of France and Holland, Luxembourg and Holland, Britain and other countries, is obvious. We make a comparison based on the above divided stages, 1973-1987, 1988-1997, 1998-2015. The test results of 1973-1987 are shown in Table 2, from which we can see that the economic correlations of France and Holland, Luxembourg and Holland and Sweden, Britain and other countries are significant. We find that especially the economic correlation of France and Holland, Swede and Luxembourg, Britain and Sweden and Luxembourg are between $0.70-0.91$, which indicates that the economic fluctuation synchronizations of these countries are very high.

Table 3 shows the correlation test results of 1988-1997. It can be seen from Table 3, that the economic correlation between France and Luxembourg, Sweden and Holland, Luxembourg and Holland, Britain and Sweden is obvious. In

Table 1. 5-Economies economic growth correlation (5 MA) (1973-2015).

\begin{tabular}{|c|c|c|c|c|c|c|}
\hline \multicolumn{2}{|c|}{ Country/project } & Holland & France & Luxembourg & Sweden & Britain \\
\hline \multirow{2}{*}{ Holland } & Correlation index & 1.0000 & & & & \\
\hline & Significance & 0.0000 & & & & \\
\hline \multirow{2}{*}{ France } & Correlation index & $0.771^{\star *}$ & 1.0000 & & & \\
\hline & Significance & 0.0000 & 1.0000 & & & \\
\hline \multirow{2}{*}{ Luxembourg } & Correlation index & $0.624^{* *}$ & $0.381^{\star *}$ & 1.0000 & & \\
\hline & Significance & 0.0000 & 0.0060 & 0.0000 & & \\
\hline \multirow{2}{*}{ Sweden } & Correlation index & $0.381^{* *}$ & $0.339^{\star}$ & $0.396^{* *}$ & 1.0000 & \\
\hline & Significance & 0.0060 & 0.0140 & 0.0050 & 0.0000 & \\
\hline \multirow{2}{*}{ Britain } & Correlation index & $0.551^{* *}$ & $0.480^{* *}$ & $0.671^{* *}$ & $0.734^{\star \star}$ & 1.0000 \\
\hline & Significance & 0.0000 & 0.0010 & 0.0000 & 0.0000 & 0.0000 \\
\hline
\end{tabular}

${ }^{* *}$ At 0.01 the correlation level is significant. 
Table 2. 5-Economies economic growth correlation (5 MA) (1973-1987).

\begin{tabular}{ccccccc}
\hline \multirow{2}{*}{ Country/project } & Holland & France & Luxembourg & Sweden & Britain \\
\hline \multirow{2}{*}{ Holland } & Correlation index & 1.0000 & & & & \\
& Significance & 0.0000 & & & & \\
France & Correlation index & $0.823^{* *}$ & 1.0000 & & & \\
& Significance & 0.0000 & 0.0000 & & & \\
& Correlation index & 0.3420 & -0.0590 & 1.0000 & & \\
Luxemburg & Significance & 0.1060 & 0.4180 & 0.0000 & & \\
& Correlation index & 0.3500 & -0.0330 & $0.840^{* *}$ & 1.0000 & \\
Sweden & Significance & 0.1000 & 0.4530 & 0.0000 & 0.0000 & \\
& Correlation index & 0.2960 & -0.0970 & $0.911^{* *}$ & $0.735^{* *}$ & 1.0000 \\
Britain & Significance & 0.1420 & 0.3660 & 0.0000 & 0.0010 & 0.0000 \\
\hline
\end{tabular}

${ }^{* *}$ At 0.01 the correlation level is significant.

Table 3. 5-Economies economic growth correlation (5 MA) (1988-1997).

\begin{tabular}{ccccccc}
\hline \multirow{2}{*}{ Country/project } & Holland & France & Luxembourg & Sweden & Britain \\
\hline \multirow{2}{*}{ Holland } & Correlation index & 1.0000 & & & & \\
& Significance & 0.0000 & & & & \\
\multirow{2}{*}{ France } & Correlation index & $0.695^{*}$ & 1.0000 & & & \\
& Significance & 0.0130 & 0.0000 & & & \\
\multirow{2}{*}{ Luxembourg } & Correlation index & 0.3020 & $0.832^{* *}$ & 1.0000 & & \\
& Significance & 0.1990 & 0.0010 & 0.0000 & & \\
\multirow{2}{*}{ Sweden } & Correlation index & $0.811^{* *}$ & 0.4100 & -0.1150 & 1.0000 & \\
& Significance & 0.0020 & 0.1200 & 0.3760 & 0.0000 & \\
\multirow{2}{*}{ Britain } & Correlation index & $0.649^{*}$ & 0.4940 & 0.0260 & $0.901^{* *}$ & 1.0000 \\
& Significance & 0.0210 & 0.0730 & 0.4710 & 0.0000 & 0.0000 \\
\hline
\end{tabular}

${ }^{* *}$ At 0.01 the correlation level is significant. ${ }^{*}$ Correlation level is significant at 0.05 .

this period, the contract based European Union Treaty, promotes the EU members to develop from a common market into an economic alliance, and it remarkably enhances the economic synchronizations between these EU economies. The economic growth correlation analysis of five countries in 1998-2015 is shown in (Table 4), correlation level between two economies is very significant, and both are in between $0.70-0.98$. This dramatically shows that the EU currency unification prompts the economic fluctuation synchronizations among EU members.

\section{The Analysis Based on C-M Synchronization Index Method}

By using C-M synchronization index calculation formula, the authors get the annual synchronization index of economic fluctuations between the two among 
five countries in 1971-2016. The annual synchronization index between each pair of the countries fluctuates greatly, making it difficult to see the change law in 1971-2016. In view of this, the authors conduct a HP filtering processing of the calculated economic synchronization index series, and then Figure 3 shows that the synchronization index trends are obtained. It can be seen from Figure 3 that, the economic fluctuation synchronizations differ greatly between countries, economic synchronizations between some countries keeping raising with the passage

Table 4. 5-Economies economic growth correlation (5MA) (1998-2015).

\begin{tabular}{ccccccc}
\hline \multirow{2}{*}{ Country/project } & Holland & France & Luxembourg & Sweden & Britain \\
\hline \multirow{2}{*}{ Holland } & Correlation index & 1.0000 & & & & \\
& Significance & 0.0000 & & & & \\
\multirow{2}{*}{ France } & Correlation index & $0.930^{* *}$ & 1.0000 & & & \\
& Significance & 0.0000 & 0.0000 & & & \\
\multirow{2}{*}{ Luxemburg } & Correlation index & $0.915^{* *}$ & $0.972^{* *}$ & 1.0000 & & \\
& Significance & 0.0000 & 0.0000 & 0.0000 & & \\
\multirow{2}{*}{ Sweden } & Correlation index & $0.809^{* *}$ & $0.919^{* *}$ & $0.913^{* *}$ & 1.0000 & \\
& Significance & 0.0000 & 0.0000 & 0.0000 & 0.0000 & \\
\multirow{2}{*}{ Britain } & Correlation index & $0.707^{* *}$ & $0.874^{* *}$ & $0.875^{* *}$ & $0.945^{* *}$ & 1.0000 \\
& Significance & 0.0010 & 0.0000 & 0.0000 & 0.0000 & 0.0000 \\
\hline
\end{tabular}

${ }^{* *}$ At 0.01 the correlation level is significant.

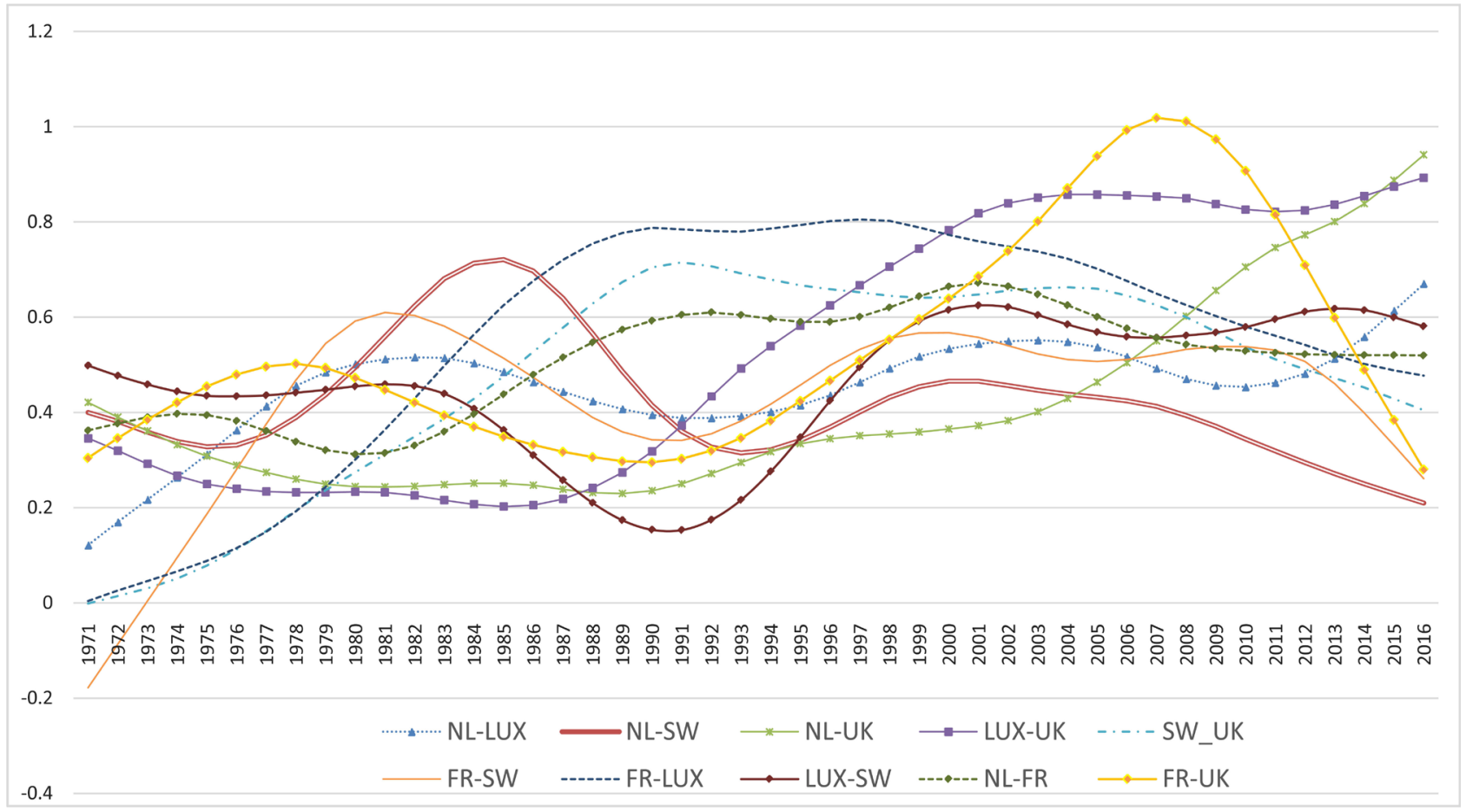

Data source: the original data is from the online database of UNCTAD

Figure 3. The economic fluctuation synchronization index (HP) of pairs of five countries. 
of time; economic synchronization level fluctuation between some countries is large, but overall the trend is on the rise; while the economic fluctuation synchronization level between some countries is in decline. Even so, Figure 3 still generally reflects that the economic fluctuation synchronization index (HP) of the two among five remains bullish, that is, in 1971-2016, the economic synchronization level of five countries is overall constantly improving.

To further analyze the economic fluctuations synchronization level between five countries, by conducting an arithmetic average of economic fluctuations synchronization index between two among five countries, the authors obtain the economic fluctuations cooperative overall level of these five countries (Figure 4). According to the calculation, in 1971-2016 the economic fluctuation average synchronization index of EU five countries is 0.48 . For the 45 -year's inspection period, this data is enough to illustrate that the economic fluctuation synchronization of these five countries is obvious. Figure 4 shows the economic fluctuation synchronization index changes of five countries can be divided into four stages 1971-1987, 1988-1997, 1998-2007 and 2008-2016, respectively experience remarkable rise, weak decline, obvious rise and rapid decline. The economic fluctuations average synchronization indexes of five countries in these four stages are

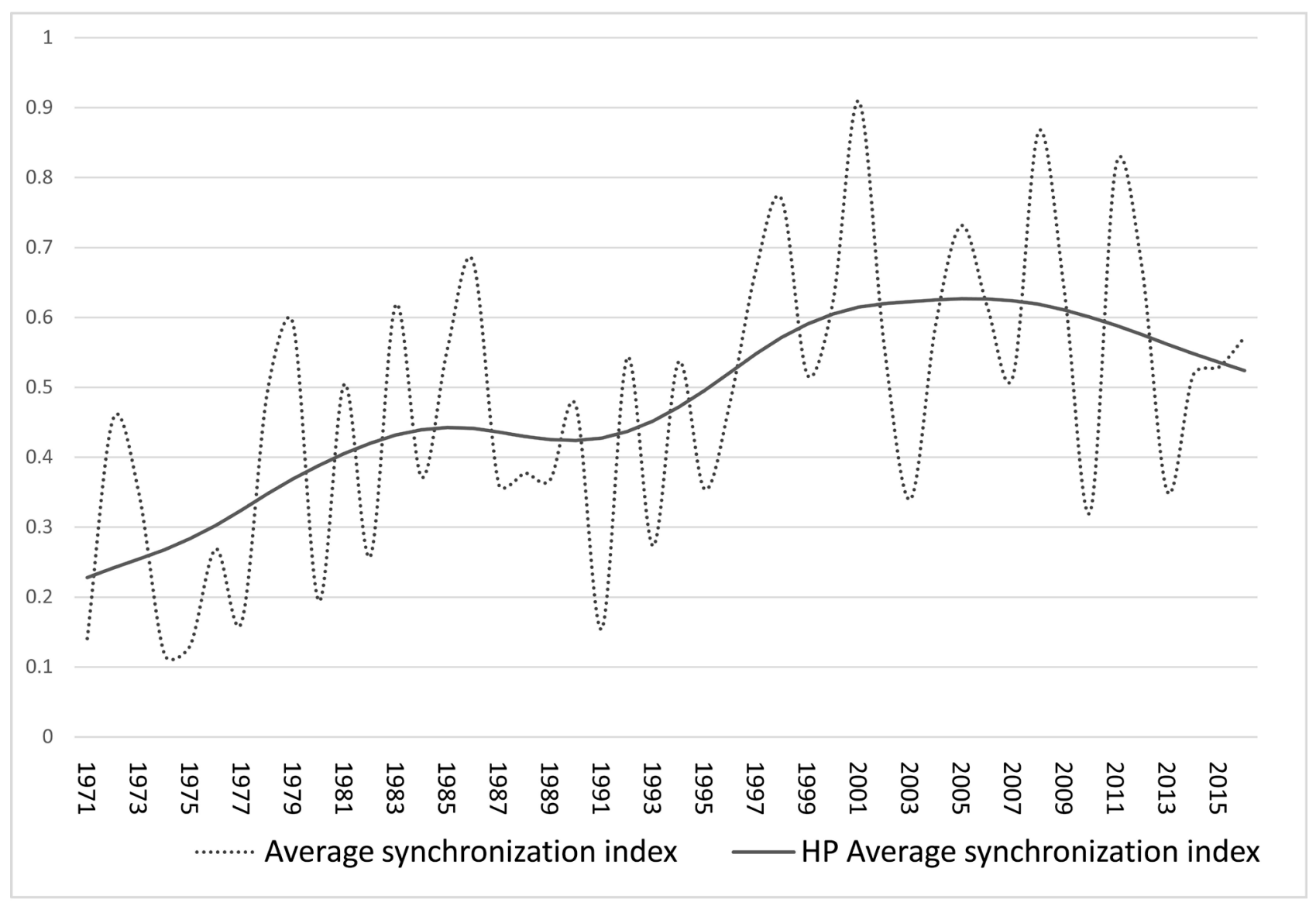

Data source: The original data is from the online database of UNCTAD.

Figure 4. The trend of economic fluctuation synchronization index of five countries. 
$0.37,0.45,0.61$ and 0.58 respectively. In the entire study period, five European countries economic fluctuation synchronization level is on the rise, that is with the deepening of EU economic integration, the economic fluctuation synchronization level advances overall.

The above researches show that European community is born under the 1965 "Treaty of Brussels", which greatly enhances the economic synchronization of member countries in European Coal and steel community, European Atomic Energy Community and the European Economic Community. However, the UK and Sweden and other EU countries, have not yet joined the European community, therefore the economic synchronization between them and other original members is not significant. But, as sample countries gradually join, the economic ties between five countries are rapidly strengthened. Especially, the formal establishment of EU, and the unified implementation of Euro as a currency implementation among the EU countries, markedly facilitate economic synchronization within the EU. This is included in our sample of five countries in 1988-1997 and 1998-2007. During the whole inspection period, the decline in economic synchronization level of five countries in 1989-1991 indicates the in-coordination triggered by the enlargement of EU and the weary global economy, but this adverse trend is gradually reversed by the EU internal coordination system, and then develops into the rapid rise of economic synchronization level after 1991. The global financial crisis in 2007, inflicted heavy losses on the European economy, plunging European Union into a debt crisis and many internal conflicts, economic synergy declined.

\section{Conclusions}

Based on the above empirical analysis, the authors draw the following basic conclusions:

First, in the study period (1971-2016), economic fluctuation synchronization of France, Holland, Luxembourg, Sweden and Britain is generally obvious. This illustrates that the integration process since the beginning of 1945, directly promotes economic policy, economic structure, industrial structure and the coordination of international cooperation of various countries.

Second, the economic fluctuation synchronization of France, Holland, Luxembourg, Sweden and Britain gradually goes forward with the deepening of European economic integration. Throughout the whole inspection period, correlation and C-M synchronization index analysis show that the economic fluctuation synchronization index of five European countries economic is in an upward trend, which indicates that the EU economic integration constantly promotes the cooperative level of economic fluctuation.

Third, the cooperative level of economic fluctuation between EU countries is not balanced. The correlation and C-M synchronization index shows that there are considerable differences between the correlation coefficient, and economic synchronization index of the two among five countries that means the differenc- 
es in economic synchronization of various countries are great, namely economic cooperation differences, which reflect that EU countries had developed an economy which became out of phrase. Especially, after the global economic crisis in 2007, the mutual accusations and conflict of EU members, in consumption, banking sector and supervision, fiscal policies, and refugee problems, become increasingly prominent, fostering EU non-harmonious force that gradually affects the economic synchronization and coordination among the countries. A British exit also confirms that the synchronization level of economic fluctuation between EU countries is unbalanced, as empirical analysis shows. Currently, the uncooperative policy and economic reality of the EU member nations is wreaking havoc on the EU as a coherent entity. Whether the EU will gradually disintegrate or remain intact has become an intensive debate topic.

\section{Funding}

This article is supported by the National Social Science Fund Project (14XJL007) of China.

\section{References}

[1] Davis, J.S. (2014) Financial Integration and International Business Cycle Co-Movement. Journal of Monetary Economics, 64, 99-111. https://doi.org/10.1016/j.jmoneco.2014.01.007

[2] Furlanetto, F., Natvik, G.J. and Seneca, M. (2013) Investment Shocks and Macroeconomic Co-Movement. Journal of Macroeconomics, 37, 208-216. https://doi.org/10.1016/j.jmacro.2013.03.005

[3] Jos Jansen, W. and Stokman, A.C.J. (2014) International Business Cycle Co-Movement: The Role of FDI. Applied Economics, 46, 383-393. https://doi.org/10.1080/00036846.2013.844327

[4] Song, L.L. and Tan, S.-L. (2011) Business Cycle Co-Movement between Australia and East Asia. Australian Economic Review, 44, 427-436. https://doi.org/10.1111/j.1467-8462.2011.00657.x

[5] Mathy, G.P. and Meissner, C.M. (2011) Business Cycle Co-Movement: Evidence from the Great Depression. Journal of Monetary Economics, 58, 362-372. https://doi.org/10.1016/j.jmoneco.2011.07.004

[6] Zhou, Y.M. (2005) World Economic Game Cycle. China Economic Publishing House, Beijing, 32-35.

[7] Liu, C.Y. (2006) Business Cycle Theory. People's Publishing House, Beijing, 134.

[8] Zhang, B. (2006) The Analysis on the Synchronization of Chinese and American Business Cycles and Its Transmission Mechanism. World Economic Studies, 10, 31-38

[9] Ren, Z.X. (2004) On the Co-Movement between China's Economic Fluctuations and the World Business Cycle. PhD Dissertation, Zhejiang University, Hangzhou, 9.

[10] Qin, A.H. (2010) A Preliminary Study on the Convergence of European Business Cycles. European Studies, No. 2, 79-941.

[11] Sun, J. and Cai, T.J. (2013) A Comparative Analysis of the Economic Changes of the Major EU Countries-Based on the Perspective of Business Cycle. Journal of Beijing Technology and Business University, No. 3, 20-26. 
[12] Jones, J., Collins, N. and Sribnick, L. (2012) External Influences on Business Cycle Synchronization in the Euro Area. International Advances in Economic Research, No. 1, 156-166. https://doi.org/10.1007/s11294-011-9339-7

[13] Weyerstrass, K., Van Aarle, B., Kappler, M., et al. (2011) Business Cycle Synchronization with (in) the Euro Area. Open Economies Review, No. 3, 86-102.

[14] Cerqueira, P.A. and Martins, R. (2009) Measuring the Determinants of Business Cycle Synchronization Using a Panel Approach. Economics Letter, 102, 106-108. https://doi.org/10.1016/j.econlet.2008.11.016

[15] Mckinnon, R. and Schnabl, G. (2003) Synchronized Business Cycle in East Asia and Fluctuations in the Yen/Dollar Exchange Rate. The World Economy, 26, 1067-1088. https://doi.org/10.1111/1467-9701.00563 